\title{
Osteogenesis imperfecta type V
}

\author{
Peter Kei Tat Hui • Joanna Y. L. Tung • \\ Wendy W. M. Lam • M. T. Chau
}

Received: 3 May 2011 /Revised: 31 May 2011 / Accepted: 4 July 2011 / Published online: 6 August 2011

(C) ISS 2011

Osteogenesis imperfecta type V was first described in 2000. It is a distinct clinical entity with unique clinical, radiological, and histological features. Clinically, it is only moderately deforming. Patients have normal sclera and teeth. Radiological diagnostic criteria include a triad of calcification of the radioulnar interosseous membrane, presence of hypertrophic callus at fractures or post-operative sites, and radiodense metaphyseal band adjacent to growth plates [1]. Histologically, it is distinguished by a mesh-like pattern of lamellation under polarized light microscopy for iliac bone samples.

Ossification of the interosseous membrane of the forearm is a constant feature, although it may vary in its extent. The presence of ossification can severely limit movements of the forearm, and is associated with secondary dislocation of the radial head $[1,2]$. The frequency of radial head dislocation/subluxation is significantly higher in type $\mathrm{V}$ osteogenesis imperfecta $(86 \%)$ than in the other types $(0 \%$ to $29 \%)$ [3]. The presence of interosseous membrane ossification in a pediatric patient, with or without radial head dislocation, should prompt radiologists to consider OI type $\mathrm{V}$ as a diagnosis.

The case presentation can be found at doi:10.1007/s00256-011-1230-3.

P. K. T. Hui $(\bowtie) \cdot$ W. W. M. Lam $\cdot$ M. T. Chau

Department of Radiology, Queen Mary Hospital, 102 Pokfulam Road,

Southern, Hong Kong, China

e-mail: peterkthui@gmail.com

J. Y. L. Tung

Department of Paediatrics and Adolescent Medicine, Queen Mary

Hospital, The University of Hong Kong,

Hong Kong, China
The formation of hypertrophic callus, if present, is the most conspicuous clinical symptom in OI type V [1]. It is reported that while not all OI type $\mathrm{V}$ patients have hypertrophic callus formation, all patients with hypertrophic callus formation are OI type $\mathrm{V}$ in the proper clinical context $[1,4]$. Lesions form during the growth years at sites of rapid periosteal apposition. The long bones are most often affected, particularly in the lower extremities [4]. Hypertrophic callus can be precipitated by fracture or surgery, or arise spontaneously. It can become very large or even mimic osteosarcoma $[2,5]$. In unclear cases, MRI and CT can be helpful in distinguishing hypertrophic callus from sarcoma [6,7]. Evolution of the lesions is variable, ranging from complete resolution to significant persisting morbidity.

\section{References}

1. Glorieux F, Rauch F, Plotkin H, et al. Type V osteogenesis imperfecta: a new form of brittle bone disease. J Bone Miner Res. 2000;15:1650-8.

2. Rauch F, Glorieux F. Osteogenesis imperfecta. Lancet. 2004;363:1377-85.

3. Fassier AM, Rauch F, Aarabi M, Janelle C, Fassier F. Radial head dislocation and subluxation in osteogenesis imperfecta. J Bone Jt Surg Am. 2007;89(12):2694-704.

4. Cheung MS, Florieux FH, Rauch F. Natural history of hyperplastic callus formation in osteogenesis imperfecta type V. J Bone Miner Res. 2007;22(8):1181-6.

5. Vieira RL, Amaral DT, Jesus-Garcia FR, Saraiva G, Fernandes AR, Resnick D. Hyperplastic callus formation in osteogenesis imperfecta type $\mathrm{V}$ mimicking osteosacroma: 4-year follow-up with resolution. Skelet Radiol. 2006;35:402-5.

6. Rieker O, Kreitner KF, Karbowski A. Hyperplastic callus formation in osteogenesis imperfecta: CT and MRI findings. Eur Radiol. 1998;8:1137-9.

7. Dobrocky I, Seidl G, Grill F. MRI and CT features of hyperplastic callus in osteogenesis imperfecta tarda. Eur Radiol. 1999;9:665-8. 